\title{
Relationship between Caregiver's Quality of Life and Childhood Tuberculosis in Bauchi State, Northeastern Nigeria
}

\author{
Haruna Ismaila Adamu1 ${ }^{*}$, Tolulope Andrea Osoba², Cornelia R. White ${ }^{2}$, \\ Yakubu Gida Abdullahi ${ }^{3}$ \\ ${ }^{1}$ Communicable and Non-Communicable Diseases Cluster, World Health Organization, Abuja, Nigeria \\ ${ }^{2}$ School of Health Sciences, Walden University, Minneapolis, MN, USA \\ ${ }^{3}$ Bauchi Agency for the Control of AIDS, Tuberculosis and Malaria (BACATMA), Bauchi, Nigeria \\ Email: ^adamuh@who.int
}

How to cite this paper: Adamu, H.I., Osoba, T.A., White, C.R. and Abdullahi, Y.G. (2018) Relationship between Caregiver's Quality of Life and Childhood Tuberculosis in Bauchi State, Northeastern Nigeria. Open Access Library Journal, 5: e4602. https://doi.org/10.4236/oalib.1104602

Received: April 16, 2018

Accepted: May 15, 2018

Published: May 18, 2018

Copyright $\odot 2018$ by authors and Open Access Library Inc.

This work is licensed under the Creative Commons Attribution International License (CC BY 4.0).

http://creativecommons.org/licenses/by/4.0/

(c) (i) Open Access

\begin{abstract}
Background: In Nigeria, childhood tuberculosis (TB), a debilitating and deadly disease, is highly prevalent and case reporting is poor due to weak health systems. Globally, children account for at least 10 percent of the TB burden, yet they remain neglected in TB prevention and control efforts. Research studies integrating family and community-centered strategies have been recommended by stakeholders to address the paucity of current local prevention and management strategies for childhood TB. Study Design: Observational study. Methods: This quantitative cross-sectional study explored the relationship between caregivers' quality of life (QOL) and the reporting of TB in their children aged 0 - 14 years. Using the abbreviated version of World Health Organization's (WHO) QOL tool, the WHOQOL-BREF, data were collected individually in a face-to-face setting from caregivers $(n=47)$ whose children had been diagnosed with TB in Bauchi State, Northeastern Nigeria, over a 5 -year period. Data were collected in the same manner from another set of caregivers of children without TB $(n=47)$ within the same period and setting. Results: Logistic regression indicated a statistically significant relationship $(p<0.001)$ between the caregivers' QOL and the reporting of childhood TB. Conclusion: This finding underscores the need to identify the factors that positively impact the QOL of caregivers of childhood TB cases. It also reflects the importance of integrating QOL interventions as part of TB control programs seeking to improve childhood TB reporting. This can mitigate the disease burden in vulnerable age-groups living in resource limited settings, thereby contributing to positive social change in the society.
\end{abstract}




\section{Subject Areas}

Public Health

\section{Keywords}

Tuberculosis, World Health Organization, Bauchi, Childhood TB, National

TB Control Programme, Caregivers, Quality of Life, Northeastern Nigeria

\section{Introduction}

Children accounted for 10\% of the global tuberculosis (TB) burden in 2016 (World Health Organization) [1], yet they remained neglected relative to preventive responses to control TB. In addition, it is well documented that TB research, prevention, and control worldwide have predominantly focused on adults, neglecting children 0 - 14 years old [2] [3] [4] [5] [6]. However, children can no longer be ignored in TB research, prevention and control, as they accounted for $10 \%$ of the total global burden in 2016 [1], 15\% in South Africa [7], $25 \%$ in Afghanistan [8], 3.4\% in India [9], 7.9\% in Peru [10], 13.7\% in Nigeria [1] and $6 \%$ in the United States [11].

TB is a public health burden in Nigeria, estimated at 407,000 cases in 2016, ranked seventh among the 30 highest TB burdened countries in the World and second in Africa [1]. Furthermore, this burden is further fueled by co-infection with HIV/AIDS as well as the emergence of drug resistant TB [12] [13]. Although curable and preventable, TB is a highly infectious disease caused by a bacterium known as mycobacterium tuberculosis which can affect any part of the body, even though the lungs remain the organs mostly affected, giving rise to pulmonary TB. Extra-pulmonary TB is that which affects any organ other than the lungs [6].

This study, however, focused on pulmonary TB in children aged 0 - 14 years. The infection is spread from person to person through the air as a result of coughing, sneezing, spitting, speaking or even singing by people with pulmonary TB [6]. A healthy person needs to inhale only a few of these bacteria to become infected. An infected person can transmit the bacteria to about 10 to 12 healthy individuals per year, although being infected with the bacteria is not synonymous with having the disease [6] [14].

Childhood TB (CTB or pediatric TB) refers to TB in children aged 0 - 14 years old [15] [16]. According to the WHO [1], children accounted for $10 \%$ of the total global burden in 2016, which translates to an estimated 1 million CTB cases and 210,000 deaths. Once infected with mycobacterium tuberculosis, children tend to progress more quickly with the disease than adults [16]. The presence of CTB in a community reflects recent and current transmission of the infection in that community, and the burden of the disease provides a clue to the level of TB prevention and control efforts being achieved in that particular setting [4]. Ad- 
ditionally, the presence of infected children in a particular community is an indication of having a reservoir of the bacteria as well as the possibility of having future cases of infections if preventive measures are not taken [5]. However, extensive literature review has shown that there is a paucity of research studies examining the relationship between CTB and caregivers' quality of life (QOL). The purpose of this study was to examine the relationship between CTB reporting and caregivers' QOL in Bauchi State, Northeastern Nigeria.

\section{Methods}

Bauchi state, nicknamed "Pearl of Tourism", is one of the six states in the northeastern region of the country, divided into 20 local government areas (LGAs) with a projected population of $6,056,519$ million people comprising of $51 \%$ males and $49 \%$ females [17]. It occupies a total land area of $49,119 \mathrm{~km}^{2}$, representing about $5.3 \%$ of the country's total land mass and is located between latitudes $9^{\circ} 3^{\prime}$ and $12^{\circ} 3^{\prime}$ north and longitudes $8^{\circ} 50^{\prime}$ and $11^{\circ}$ east. It is multiethnic and multilingual in nature with an estimated 55 tribal groups, with Hausa Language being the most widely spoken across all parts of the state. The economy is driven essentially by agriculture and tourism apart from few manufacturing industries in iron, steel, water, ceramics, food and beverages. The vast fertile soil and water resources available in the state makes crops production and animal husbandry the main stay of its economy, coupled with the presence of the famous Yankari Game Reserve, which is said to be the biggest game reserve in West Africa [18].

The study was a cross-sectional survey of caregivers whose children had been diagnosed with CTB in Bauchi State, Northeastern Nigeria from January 1, 2011 to December 31, 2015 as recorded in the State Ministry of Health CTB database. The QOL was measured through face-to-face interviews with a sample of caregivers, using an internationally recognized tool developed and used by the WHO, the WHOQOL-BREF questionnaire [19]. It comprises of 26 questions, 24 of which are spread in four domains: physical, psychological, social relations, and environment. These domains consisted of seven, six, three, and eight questions respectively. The questions were measured on a five-point scale ranging from 1 to 5 . The domain scores were scaled in a positive direction. The overall well-being of the respondents was dichotomized into poor or good based on WHO standard procedures. The remaining two questions are general: One linked to the self-perceived QOL and the other to contentment with health. Summed scale scores for all the items within the QOL measure were created. Additionally, transformed scale scores were also created as per the scoring instructions provided on the WHO-QOL BREF questionnaire. These were the scores used in the analysis.

All respondents had signed consent forms before being interviewed. The questions ascertained information on the caregivers' QOL and excluded all personal identifiers such as names, street addresses, and telephone numbers so as to 
ensure that the collected data remains confidential, in accordance with the general conduct of ethical biomedical studies as defined by the WMA Declaration of Helsinki in 1964 and revised in 2013 [20]. Information on CTB was extracted and reviewed retrospectively by the researchers, from the Bauchi State CTB database for the 5-year period, taking care to avoid double reporting.

The inclusion criteria included 1) only children aged 0 - 14 years old diagnosed by a physician with CTB, 2) all cases would have to meet WHO/National Tuberculosis Programme (NTP) case definition for CTB [15] [16], 3) all cases diagnosed and treated in any of the eight selected DOTS treatment centers, and, 4) all CTB cases diagnosed and treated between January 01, 2011 to December 31, 2015. Conversely, the exclusion criteria included: a) all children outside the 0 14 year age range, b) all cases that have not met the WHO/NTP case definition for CTB, c) all CTB cases diagnosed and treated outside the NTP and/or within facilities that are not designated as DOTS treatment centers by the NTP, and, d) all CTB cases diagnosed before January 1, 2011 or after December 31, 2015.

The sample size for the study was determined using the formula, $n=\frac{z^{2} p q}{d^{2}}$ [21]. The formula was utilized in a similar cross-sectional study conducted by [22] in order to assess the attitude of public health workers in Calabar, Cross River State of Nigeria, towards people living with HIV/AIDS using the AIDS attitude scale. Similarly, [23] used the formula to determine the sample size in an experimental study of HIV positive patients on care and treatment in Kisumu District, Nyanza Province, Kenya.

Assuming a non-response rate of $20 \%$, the minimum required sample size was 53 , where, $6 \%=$ proportion of Nigerian children aged $0-14$ years diagnosed with TB in 2014 [24]. Therefore, the sample size for the study was 53 caregivers of CTB cases. Bearing in mind that Bauchi State has a total population of 6,056,519 people, 3 geopolitical zones, 20 Local Government Areas (LGAs), and 196 directly observed treatment, short-course (DOTS) treatment centers, a representative sample of these 53 caregivers of CTB cases were obtained using the multi-staged sampling technique. These were proportionally contributed by each of the 8 randomly selected DOTS centers through systematic random sampling technique [25].

\section{Statistical Analysis}

Data generated for this study was analyzed using SPSS version 21 [26]. Demographic characteristics of the respondents such as gender, age, and marital status were analyzed. The relationships between caregivers' QOL and the reporting of CTB were determined by MLR model. The reporting of CTB was measured as a dichotomous variable where $0=$ no TB and $1=\mathrm{TB}$ present. Therefore, based on the sample size calculation above, 53 caregivers of CTB cases and 53 caregivers of children without CTB (controls) were randomly selected and interviewed face to face with the help of the WHO-QOL BREF questionnaire. The assumptions 
for this test include the fact that the dependent variable is dichotomous, and has been coded as such; all the variables in the WHOQOL-BREF questionnaire would be included in the analyses; and the fact that an adequate sample size would be calculated. All these assumptions were met.

\section{Ethical Clearance}

Permission to conduct this research was sought and obtained from Bauchi State Ministry of Health's Research Ethics Committee (HREC), after providing written assurances that the study would be strictly for academic research purposes and that its outcomes would be meted with utmost confidentiality. The ministry was further assured that identifiers such as the name of CTB patients, their parents and/or caregivers, addresses were coded to safeguard against identification by people outside the research community. Secondly, each of the potential participants was adequately informed about the study to enable him/her decide whether to participate or not. For those who agreed to participate, a written consent was obtained from each one of them in line with ethical standards [20].

\section{Results}

Out of the 53 invited caregivers of CTB cases, a total of 47 (88.7\%) agreed to participate and were interviewed by the researchers face to face in their communities of residence after signing an informed consent form. Similarly, the same number of caregivers without $\mathrm{TB}$ were interviewed in the same manner and setting as control population. Thus, the data obtained from the 94 interviewed caregivers was subjected to descriptive and inferential statistics using the SPSS version 21. As shown in Table 1, majority of the respondents in both groups were males $(63.8 \%$ and $57.4 \%)$, young within the reproductive age group of $18-49$ years $(76.6 \%$ and $80.8 \%)$ and married $(80.9 \%$ and $83.9 \%)$. However, respondents whose children had no TB appear to be more educated, as 34 of them (72.4\%) either attended high school or college, than those whose children had TB, where less than half of them (23\% or $49 \%)$ attended either high school or college.

Furthermore, the mean and standard deviation (SD) for overall QOL rating as well as for those of the other four QOL domains for the respondents (each of the two groups separately and then combined) have been determined with the help of SPSS. For instance, the overall QOL rating for respondents whose children do not have TB appears to be higher (mean 7.87 and SD 1.84) as compared with that of respondents whose children have TB (mean 6.85 and SD 1.37). This difference was statistically significant $(p<0.01)$ as shown in Table 2 . Likewise, the scores for each of the four QOL domains were higher in respondents whose children do not have TB than in respondents whose children have TB and these differences were statistically significant $(p<0.01)$. These findings suggest that respondents whose children do not have TB have higher QOL than those whose children have TB. 
Table 1. Demographic characteristics of respondents.

\begin{tabular}{ccccccc}
\hline \multirow{2}{*}{ Demographics } & $\begin{array}{c}\text { Number } \\
\text { of } \\
\text { Children } \\
\text { with TB }\end{array}$ & $\begin{array}{c}\text { Number of } \\
\text { Children } \\
\text { without TB }\end{array}$ & $\begin{array}{c}\text { \% Children } \\
\text { with TB }\end{array}$ & $\begin{array}{c}\text { \% Children } \\
\text { without TB }\end{array}$ & Total \\
\hline \multirow{2}{*}{ Gender } & Male & 30 & 27 & 63.8 & 57.4 & 57 \\
& Female & 17 & 20 & 36.2 & 42.6 & 37 \\
& $18-29$ & 15 & 16 & 31.9 & 34.0 & 31 \\
\multirow{4}{*}{ Age } & $30-39$ & 13 & 12 & 27.7 & 25.5 & 25 \\
& $40-49$ & 8 & 10 & 17.0 & 21.3 & 18 \\
& $50-59$ & 7 & 8 & 14.9 & 17.0 & 15 \\
Marital & $60+$ & 4 & 1 & 8.5 & 2.1 & 5 \\
Status & Single & 4 & 3 & 8.5 & 6.4 & 7 \\
& Married & 38 & 39 & 80.9 & 83.0 & 77 \\
& Divorced & 2 & 2 & 4.3 & 4.3 & 4 \\
& Widowed & 3 & 3 & 6.4 & 6.4 & 6 \\
\hline
\end{tabular}

Table 2. WHO QOL scale table of means for children with and without TB.

\begin{tabular}{|c|c|c|c|c|c|c|c|}
\hline & \multicolumn{2}{|c|}{ Children with $\mathrm{TB}$} & \multicolumn{2}{|c|}{$\begin{array}{c}\text { Children } \\
\text { without TB }\end{array}$} & \multicolumn{2}{|c|}{ Total } & \multirow{2}{*}{ p-value } \\
\hline & Mean & $\begin{array}{l}\text { Standard } \\
\text { Deviation }\end{array}$ & Mean & $\begin{array}{l}\text { Standard } \\
\text { Deviation }\end{array}$ & Mean & $\begin{array}{l}\text { Standard } \\
\text { Deviation }\end{array}$ & \\
\hline $\begin{array}{l}\text { Overall QOL } \\
\text { Rating }\end{array}$ & 6.85 & 1.367 & 7.87 & 1.837 & 7.36 & 1.690 & 0.003 \\
\hline $\begin{array}{c}\text { Physical Health } \\
\text { Scale Score } \\
\text { (Transformed) }\end{array}$ & 58.51 & 11.38 & 72.26 & 20.89 & 65.39 & 18.11 & 0.000 \\
\hline $\begin{array}{l}\text { Psychological } \\
\text { Health Scale } \\
\text { Score } \\
\text { (Transformed) }\end{array}$ & 55.14 & 11.53 & 63.65 & 15.80 & 59.40 & 14.41 & 0.004 \\
\hline $\begin{array}{c}\text { Social } \\
\text { Relationships } \\
\text { Score } \\
\text { (Transformed) }\end{array}$ & 57.09 & 15.44 & 67.73 & 14.50 & 62.41 & 15.83 & 0.001 \\
\hline $\begin{array}{c}\text { Environmental } \\
\text { Score } \\
\text { (Transformed) }\end{array}$ & 47.88 & 11.51 & 69.15 & 14.71 & 58.51 & 16.94 & 0.000 \\
\hline
\end{tabular}

\section{Discussion}

The purpose of the study was met through face to face interviews with both caregivers of children with $\mathrm{TB}$ and caregivers of children without $\mathrm{TB}$, administered using the WHOQOL-BREF questionnaire. Majority of the caregivers in both groups were males (63.8\% and 57.4\%). This finding contrasts with similar studies that showed a majority of the caregivers of children with chronic diseases to be females [27] [28]. Furthermore, majority of the caregivers in both groups 
were young within the 18 - 49 age group (76.6\% and $80.8 \%)$ and married $(80.9 \%$ and $83.9 \%$ ). However, caregivers of CTB cases had a lower literacy level (as only $49 \%$ of them attended either high school or college) compared with the control group, where $72.4 \%$ of them attended either high school or college. These findings were similar to those discovered in India and Egypt that also found low literacy levels among caregivers of CTB cases [29] [30].

The overall QOL for respondents whose children do not have TB appears to be higher (mean 7.87 and SD 1.84) compared with respondents whose children have TB (mean 6.85 and SD 1.37). This difference was statistically significant $(p<$ 0.01). Likewise, the scores for each of the four QOL domains were higher in respondents whose children do not have TB than in respondents whose children have TB and these differences were statistically significant $(p<0.01)$. These findings suggest that respondents whose children have TB have impaired QOL compared with those whose children do not have TB. This is consistent with the findings of several studies that measured the QOL of adult caregivers whose children suffered from chronic diseases such as osteogenesis imperfecta [27], sickle cell disease [31], cancer [32] [33], disabilities, Down's syndrome [34], speech and language disorders [35], COPD [28], and schizophrenia [36]. All these studies revealed that the caregivers of the diseased children had impaired QOL compared with control populations.

Thus, the QOL of women of child bearing age, parents and other caregivers should be improved, since this would have a direct relationship to the well-being of their children. This is even more expedient given the patriarchal nature of our society, where men tend to dominate over women in all aspects of life [37]. Improving the QOL of women in a patriarchal society entails giving them proper atmosphere where they can voice their opinions against inequalities and the gender-gap they are going through as well as improving their status in every aspect [37].

Moreover, improvement in the QOL of caregivers would involve multiple sectors other than health such as food security, housing, security of lives and property, provision of clean drinking water, qualitative education, and creation of jobs. Clearly, these are responsibilities of policy makers holding political offices. For the health sector, public health authorities should give priority attention to health promotion activities, preventative and curative health care services.

\section{Study Limitations}

Limitations of this study are those inherent in cross sectional designs such as selection and information (interviewer) biases as well as confounding [38]. The former was controlled through randomization of the study participants while the latter was controlled because the author personally interviewed all the study participants face to face using a standard valid tool, the WHOQOL-BREF questionnaire, thereby reducing differential misclassification to the barest minimum 
[38]. Confounding was controlled by matching the age and gender of each child with TB with another child without TB [39]. This ensured that the study participants do not differ significantly with respect to possible confounders of age and gender.

\section{Conclusion}

This study found a statistically significant relationship between the caregivers' QOL and reporting of TB in their children there by establishing a vital evidence for all stakeholders to put all hands on deck towards improving the QOL of caregivers, including empowering them socio-economically as a panacea for the prevention and control of TB in their children. This research study should, however, be replicated in other parts of the country in order to determine if findings would significantly differ between one region/state to the other, in view of the multiethnic and multicultural nature of Nigeria.

\section{Acknowledgements}

The authors wish to acknowledge that approval to conduct this research as well as to access and use the five-year CTB dataset was obtained from Bauchi State Health Research Ethics Committee (HREC) under the Ministry of Health.

\section{Conflicts of Interest}

The authors wish to declare that there is no any conflict of interest or royalty attached to this study.

\section{References}

[1] World Health Organization. (2017) Global Tuberculosis Report. http://www.who.int/tb/publications/global_report/en/

[2] Daniel, O.J., Adejumo, O.A., Abdur-Razzaq, H.A. and Ebunoluwa, J.O. (2015) Trend of Childhood TB Case Notification in Lagos, Nigeria, 2011-2014. International Journal of Mycobacteriology, 4, 239-244. https://doi.org/10.1016/j.ijmyco.2015.05.010

[3] Erkens, C.G., de Vries, G., Keizer, S.T., Slump, E. and van den Hof, S. (2014) The Epidemiology of Childhood Tuberculosis in the Netherlands: Still Room for Prevention. BMC Infectious Diseases, 14, 295. https://doi.org/10.1186/1471-2334-14-295

[4] Hamzaoui, A., Yaalaoui, S., TritarCherif, F., Slim Saidi, L. and Berraies, A. (2014) Childhood Tuberculosis: A Concern of the Modern World. European Respiratory Update, Tuberculosis, 23, 278-291. https://doi.org/10.1183/09059180.00005314

[5] Swaminathan, S. and Rekha, B. (2010) Pediatric Tuberculosis: Global Overview and Challenges. Clinical Infectious Diseases, 50, 184-194.

https://doi.org/10.1086/651490

[6] World Health Organization. (2013) Tuberculosis. http://www.who.int/topics/tuberculosis/en/

[7] Bélard, S., Isaacs, W., Black, F., Bateman, L., Madolo, L., Munro, J. and Zar, H.J. (2015) Treatment of Childhood Tuberculosis: Caregivers' Practices and Perceptions 
in Cape Town, South Africa. Pediatrics and International Child Health, 35, 2428. https://doi.org/10.1179/2046905514Y.0000000133

[8] Nelson, L. and Wells, C. (2004) Global Epidemiology of Childhood Tuberculosis. The International Journal of Tuberculosis and Lung Disease, 8, 636-647.

https://www.theunion.org/what-we-do/journals/ijtld

[9] Mukherjee, A., Chowdhury, R., Singla, R., Saha, I., Dutta, R. and Das, T. (2014) Comparison between Childhood and Adult Tuberculosis in a Rural Tuberculosis Unit of West Bengal: A Retrospective Study. Lung India: Official Organ of Indian Chest Society, 31, 116-120. https://doi.org/10.4103/0970-2113.129818

[10] Chiang, S.S., Roche, S., Contreras, C., Alarcon, V., del Castillo, H., Becerra, M.C. and Lecca, L. (2015) Barriers to the Diagnosis of Childhood Tuberculosis: A Qualitative Study. International Journal of Tuberculosis and Lung Disease, 19, 1144-1152. https://doi.org/10.5588/ijtld.15.0178

[11] Cruz, A. and Martinez, B. (2015) Childhood Tuberculosis in the United States: Shifting the Focus to Prevention. International Journal of Tuberculosis and Lung Disease, 19, S50-S53. https://doi.org/10.5588/ijtld.15.0418

[12] Getahun, H., Gunneberg, C., Granich, R. and Nunn, P. (2010) HIV Infection-Associated Tuberculosis: The Epidemiology and the Response. Clinical Infectious Diseases, 50, S201-S207.

[13] Nieburg, P. and Angelo, S. (2015) Tuberculosis in the Age of Drug Resistance and HIV. Lessons from South Africa's Experience.

http://csis.org/files/publication/150921_Nieburg_TBAgeOfDrugResistance_Web.pd $\underline{\mathrm{f}}$

[14] Centers for Disease Control and Prevention. (2012) Tuberculosis. http://www.cdc.gov/tb/topic/basics/default.htm

[15] World Health Organization. (2015) Global TB Progammme. http://www.who.int/tb/publications/GTBcorporate_factsheet.pdf

[16] Centers for Disease Control and Prevention (2014) TB in Children in the United States. http://www.cdc.gov/tb/topic/populations/tbinchildren/default.htm

[17] National Population Commission (2014) Nigeria Demographic and Health Survey 2013. https://dhsprogram.com/pubs/pdf/FR293/FR293.pdf

[18] ALL.BIZ: Nigeria (2016) Bauchi State: Economy. http://www.ng.all.biz/economy-bauchi-state-srd4008

[19] World Health Organization (1994) The World Health Organization Quality of Life (WHOQOL). http://www.who.int/mental_health/publications/whoqol/en/

[20] World Medical Association (2016) Declaration of Helsinki: Ethical Principles for Medical Research Involving Human Subjects.

[21] Naing, L., Winn, T. and Rusli, B.N. (2006) Practical Issues in Calculating the Sample Size for Prevalence Studies. Archives of Orofacial Sciences, 1, 9-14. http://www.dental.usm.my/

[22] Etokidem, A., Oparah, S., Asibong, U., Ndifon, W. and Nsan, E. (2016) Assessment of the Attitude of Public Health Workers in Calabar, Cross River State of Nigeria, towards People Living with HIV/AIDS Using the AIDS Attitude Scale. Ibom Medical Journal, 9, 1-8. http://new.ibommedicaljournal.com/

[23] Mugwe, J.N. and Mbaja, D. (2013) Comparison between FACSCalibur and FACSCount Analyzers of CD4 Counts. International Journal of Scientific and Research Publications, 3. http://www.ijsrp.org/

[24] World Health Organization (2018) Global Tuberculosis Report. 
http://www.who.int/tb/publications/global_report/en/

[25] Martínez-Mesa, J., González-Chica, D.A., Duquia, R.P., Bonamigo, R.R. and Bastos, J.L. (2016) Sampling: How to Select Participants in My Research Study? Anais Brasileiros de Dermatologia, 91, 326-330. https://doi.org/10.1590/abd1806-4841.20165254

[26] SPSS (2012) IBM SPSS Statistics for Windows, Version 21.0. IBM Corp., Armonk, NY.

[27] Vanz, A.P., Felix, T.M., Sica da Rocha, N. and Schwartz, V.D. (2015) Quality of Life in Caregivers of Children and Adolescents with Osteogenesis Imperfecta. Health and Quality of Life Outcomes, 13, 41. https://doi.org/10.1186/s12955-015-0226-4

[28] Kumar, S., Matreja, P.S., Gupta, A.K., Singh, A. and Garg, P. (2012) To Assess the Quality of Life (QOL) of Caregivers and Patients Suffering from Chronic Obstructive Pulmonary Disease (COPD). Journal of Allergy and Therapy, S2, 003.

[29] Abd Allah, E.S. (2014) The Effect of Health Education Intervention on Tuberculosis Patients and Their Caregivers.

http://english.zu.edu.eg/Details.aspx? ID =4385\&CatID=17

[30] Jani, Y., Bhambhani, G. and Thakor, N. (2015) Knowledge and Awareness of Tuberculosis in Caregivers of Pediatric Tuberculosis Patients of North Gujarat Region, India: A Cross Sectional Study. International Journal of Research in Medical Sciences, 3, 3572-3575. https://doi.org/10.18203/2320-6012.ijrms20151401

[31] Van den Tweel, X.W. (2009) Quality of Life of Female Caregivers of Children with Sickle Cell Disease: A Survey. Haematologica, 93, 588-593.

http://www.haematologica.org/ https://doi.org/10.3324/haematol.11610

[32] Rubira, E.A., Marcon, S.R., Belasco, A.G.S., Gaíva, M.A.M. and Espinosa, M.M. (2012) Burden and Quality of Life of Caregivers of Children and Adolescents with Chemotherapy Treatment for Cancer. Acta Paulista de Enfermagem, 25, 567-573. http://www.scielo.br/ https://doi.org/10.1590/S0103-21002012005000020

[33] Sajjadi, H., Vameghi, M., Ghazinour, M. and Khodaie-Ardakani, M. (2013) Caregivers' Quality of Life and Quality of Services for Children with Cancer: A Review from Iran. Global Journal of Health Science, 5, 173-182. https://doi.org/10.5539/gjhs.v5n3p173

[34] Bain, M.G. and Hoon, O.P. (2015) Caregivers of Children with Disabilities in Sarawak: Quality of Life and Its Associated Factors. http://www.fmhs.unimas.my/images/downloads/CMPH_bulletin_2.pdf

[35] Zerbeto, A.B. and Chun, R.Y. (2013) Quality of Life of Caregivers of Children and Adolescents with Speech and Language Disorders. CoDAS, 25, 128-134.

http://www.scielo.br/ https://doi.org/10.1590/S2317-17822013000200007

[36] Panigrahi, S., Acharya, R.K., Patel, M.K. and Chandrani, K.V. (2014) Quality of Life in Caregivers of Patients with Schizophrenia and Its Correlation with Severity of Illness. The International Journal of Engineering and Science, 3, 55-60. https://pdfs.semanticscholar.org/96e1/015b7ec943b2a03ee6cfb10292ad92a60f76.pdf

[37] Patowary, H. (2014) Portrayal of Women in Indian Mass Media: An Investigation. Journal of Education \& Social Policy, 1, 84-92. http://jespnet.com/

[38] Frankfort-Nachmias, C. and Nachmias, D. (2008) Research Methods in the Social Sciences. 7th Edition, Worth, New York.

[39] Pourhoseingholi, M.A., Baghestani, A.R. and Vahedi, M. (2012) How to Control 
Confounding Effects by Statistical Analysis. Gastroenterology and Hepatology from Bed to Bench, 5, 79-83.

https://www.ncbi.nlm.nih.gov/labs/journals/gastroenterol-hepatol-bed-bench/ 